\title{
Web-Based Orphanage Fundraising Information System
}

\author{
Phitsa Mauliana ${ }^{1}$, Ricky Firmansyah ${ }^{2}$, Ai Surtika Dewi ${ }^{3}$ \\ \{phitsa.phu@gmail.com ${ }^{1}$, ricky.rym@bsi.ac.id ${ }^{2}$, surtikadewiai@gmail.com ${ }^{3}$ \}
}

AMIK BSI Bandung, Jl. Sekolah Internasional No. 1-6 Bandung ${ }^{1,2}$, STIE Wikara, Jl. Jend. Ahmad

Yani No.21 Purwakarta ${ }^{3}$

\begin{abstract}
Today in Indonesia there are still many orphanages which have many financial, facilities, and affection limitations considering the orphanage is a place where children are abandoned by their parents. This research proposes implementation the "ePanti" web-based orphanage information system as a means of raising donations. Through this system, benefactors will be able to see profiles of orphanages, lists of orphans, orphanage activities, and how to make donations. This system was developed by the waterfall method which was designed using the Unified Modeling Language (UML) architecture diagram and implemented into the PHP web programming languages using MySQL database system. The system is tested using Black box testing to ensure system functionality and user acceptance tests using questionnaires. The results of this study are the development of the "e-Panti" web-based orphanage information system with a user acceptance rate of $77.50 \%$ based on the the questionnaire results.
\end{abstract}

Keywords: Donation, Information System, Internet, Orphanage, Website

\section{Introduction}

One source of funds and donations to orphanages in various developed and developing countries comes from several online donation sites on the internet. However, these sites currently do not have transparency and a way to engage benefactors to actively increase donation participation. At present, benefactors who are interested in making donations often must personally search for a social organization or orphanage. With such conditions, an individual would certainly not be interested in donating their time and money. Today in Indonesia there are still many orphanages which have many financial, facilities, and affection limitations considering the orphanage is a place where children are abandoned by one or even both parents. In addition, families who are unable to also sometimes leave their children in an orphanage. Therefore, donations from various parties are needed to support the growing number of foster children such as food, foster children's education, electricity / water tuition fees and so on. Not a few are also orphanages who are trying to be more independent to support their foster children to teach foster children not to always rely on and expect donations, for example by implementing entrepreneurship that is run by individuals or working together [1]. With such conditions, an individual would certainly not be interested in donating their time and money. The benefactors not only have access to information about how donations will be used, by whom, and what their impact will be, but will also provide a 
more interactive platform for benefactors to remain interested and connected to the orphanage offline because the orphanage can directly communicate their needs [2].

This study aims is to propose implementation of a web-based orphanage information system as a means of raising donations. Through this system, benefactors will be able to view orphanage profiles, orphanage lists, orphanage schedules, how to make donations and display a list of benefactors (who are willing to display). It is hoped that with this information system, the orphanage can be better known through the complete information on the website and knock on the days of the benefactors to make donations. The donations that can be given are not only in the form of money, but can also be in the form of goods, food, clothing, endowments, grants, training / education and so on. Thus, this research needs to be done in order to help orphanages that do not receive enough attention to be better known / known to the public / benefactors. Indirectly more will help orphans who are less fortunate in particular and in general will assist the state in realizing the mandate of the 1945 Constitution Article 34 paragraph 1 which states that "The poor and displaced children are cared for by the state" . The proposing team's roadmap focuses on developing web-based information systems and their use in business, education and social affairs.

The system is a set of elements that have the same liquidity with each other that works together to achieve goals. The system can be either abstraction or physical, abstract system is a concept that is arranged in an orderly and interconnected way. While the system with physical characteristics is a set of elements that work together to achieve a goal [3]. The benefit of the system is to combine all the elements that exist in a scope, where each component can not stand alone. Components or sub-systems are required to integrate with each other to form a single unit so that the system's goals can be achieved. Data is a collection of facts that are not organized and have no meaning. Data processing will turn it into information that is more useful, easily understood and utilized in making a decision. There are three aspects that determine the quality of information, namely [3]:

1. Accurate, namely information must explain what is meant and minimal errors.

2. Be on time, that is, the information conveyed should not be delayed. Information that is out of date will reduce the value of its benefits, considering that information is a reference in taking decision.

3. Relevant, that is, information must have benefits for the recipient. A relevance information for every one person and the other must be different so it must be in accordance with each other's needs.

Website is a collection of web pages stored in hosting and has a domain or subdomain name so that it can be accessed via the Internet. All publications on the website will form a very large information network. Like a book, a web page can hold a variety of information about all things that are commercial or not. The website began to be known in Indonesia since the 1998s which only owned by large-scale companies [4]. Unified Modeling Language (UML) Architecture Diagram is a method to describe a system designed with the aim of making it easier for programmers to make programs using object-oriented programming languages (Object Oriented Programming, OOP). UML contains diagrams that show how a system works. There are many UML diagrams, but not all diagrams must be used, adapted to their needs. UML will be a guide for a programmer in implementing it using a programming language (coding) [5]. The programming language used in this study is PHP object-oriented programming language MySQL as a database processing system. PHP is often combined with MySQL to develop a web application. MySQL functions as a place to store data (database) while PHP is the language that manages the database. Actually, PHP can not only be combined with MySQL alone. Whereas the use of MySQL as a database management system 
(DBMS) is due to its popularity and reliability as well as its open source licenses. In the development of a dynamic website, PHP is often used with MySQL to store data entered by the user [4].

Orphanage is an institution that accepts, accommodates and takes care of children who have been abandoned by one or both parents, neglected or underprivileged children (poor people) so that these children can continue their education. Orphans are very important position especially in Islam, orphans should not be underestimated, set aside and hurt and deprived of their rights. In Islam, an orphan is a child who has been abandoned by his parents and becomes a child who must be respected, glorified and even considered his future [6].

\section{Method}

This study uses the waterfall as a method of developing the system illustrated in Figure 1. Waterfall method is a method that is widely used for the design of a system in sequence where the previous stage will be input for the next stage. The advantage of the waterfall model method is the flexibility of the schedule that can be arranged in such a way as to span the time for each stage of development. The system development begins with the concept of analysis, implementation, testing, and finally the operation and maintenance In general [7]. The waterfall sequence in this study is:

1. Requirements Analysis is the stages of system requirements analysis like to know the existing problems, interviews (with orphanage managers, orphanage children and donors) and literature studies (from journals, books and internet). All information must be obtained as completely as possible for the system to be made according to need.

2. System Design is the stages of system design as a solution of existing problems by UML diagrams utilizing system modeling tools.

3. Implementation of the system using PHP program code. This stage is carried out by the programmer and is the core stage in working on a system.

4. Program Testing which is the final stage in the design of the system to ensure the system can run as expected. Testing at this stage is technical by internal system designers using Black box testing (alfa test) and external using questionnaire (beta test).

5. The information system that has been created and then implemented, while maintenance is needed to keep the system working properly. 


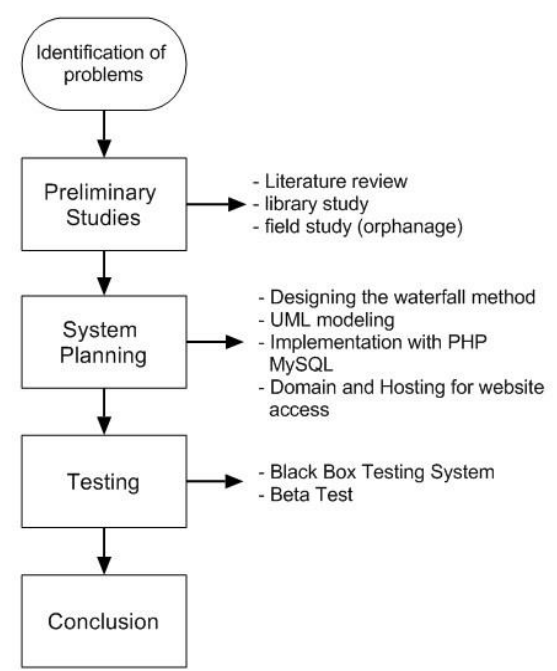

Fig. 1. Research flow.

\section{Results}

\subsection{Use case diagram}

There are 3 actors in this system, namely admin, donors and foster children, illustrated in Figure 2. Admin has full access rights starting from user verification, managing news, activity information, managing users and so on. Foster child actors have access rights to manage profiles, view activity information and view galleries. Donor actors have access rights to manage profiles, manage donations, and view institution information.

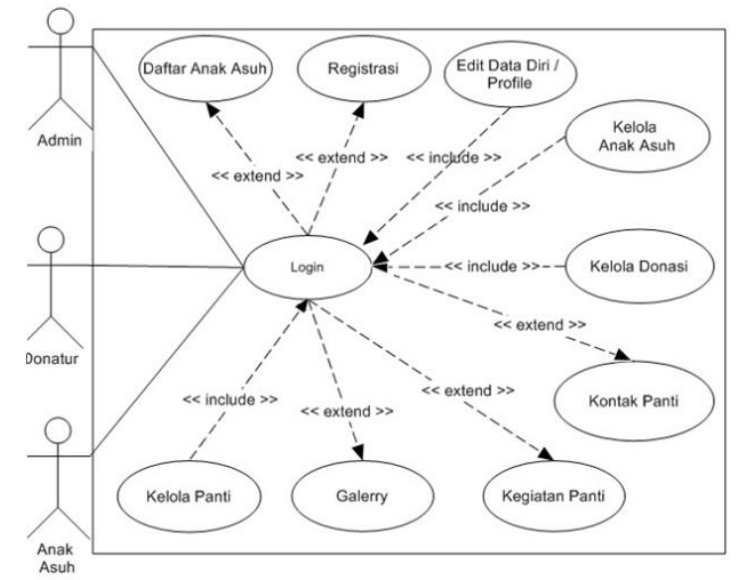

Fig. 2. Use case e-Panti. 


\subsection{System implementation}

The donation page shown in Figure $\mathbf{3}$ can be accessed by all users so that they can make donations directly and easily. Donors can also see the list of names on the list of e-Panti donors (if they wish to be displayed).

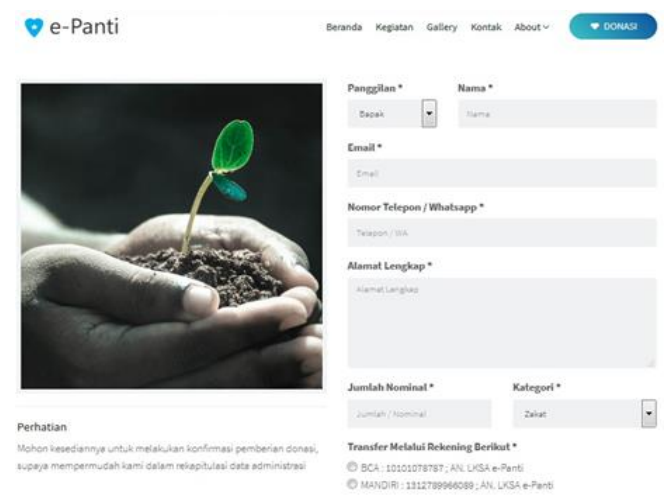

Fig. 3. Donstion page.

Each user can view the gallery shown in Figure $\mathbf{4}$ on the home information system. This gallery is a collection of photos of activities from the orphanage. The photo gallery page can be accessed by selecting the "Gallery" menu on the e-Panti information system website.

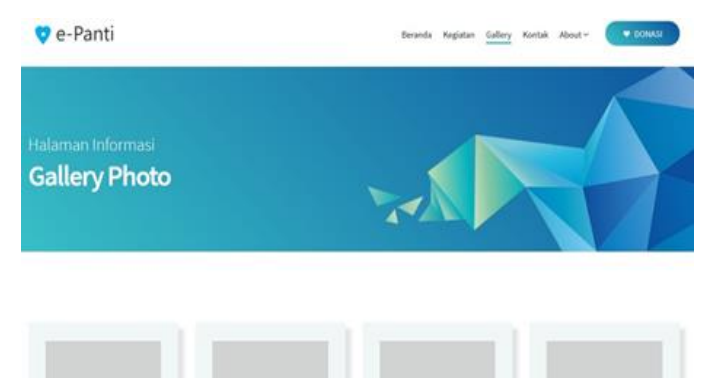

Fig. 4. Gallery.

Each user can view the gallery on the home information system. This gallery is a collection of photos of activities from the orphanage. The photo gallery page can be accessed by selecting the "Gallery" menu on the e-Panti information system website. 
The contact page on this e-Panti system shown in Figure 5 can be accessed without the need to register or log in first. Users can directly contact the orphanage admin via the contact page available in this information system.

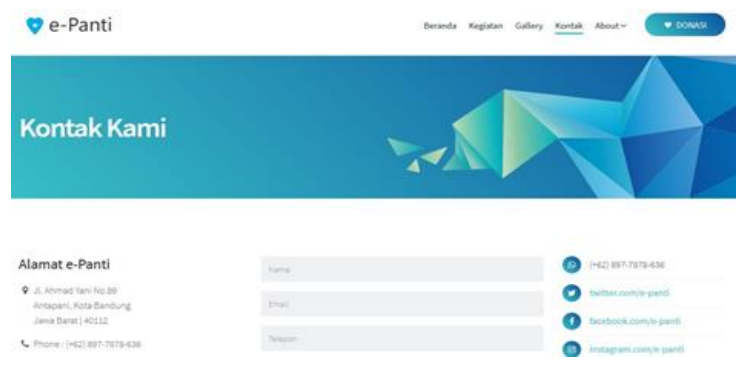

Fig. 5. Contact page.

The orphanage information system home page shown in Figure 6 is on the main web page. Here users can access and know various information in the form of vision and mission from the orphanage. Users and donors can learn about the various features of this information system through the tab menu and navigation available on the orphanage's website.

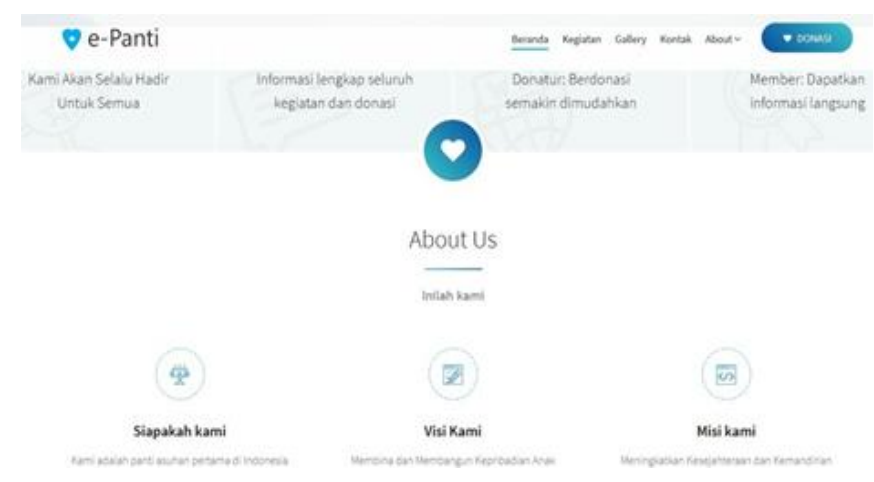

Fig. 6. Home page.

Admin dashboard page shown in Figure 7 is the initial display page when the admin login to the system. Here the admin can access and view the page manage donations, manage orphans, reports, users. In general the admin can manage data on the system as a whole. 


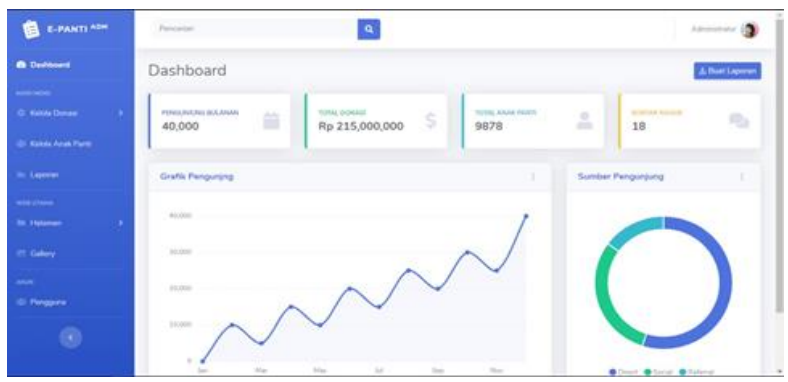

Fig. 7. Admin dashboard page.

\subsection{Black box testing (alfa test)}

Black Box Testing is done by observing the results of the execution of all commands on the system. Through this test, the system is tested in terms of functionality. In Table 1 below is a recap of the Black Box e-Panti test results.

Table 1. Black box testing.

\begin{tabular}{lll}
\hline \multirow{2}{*}{ Function } & \multicolumn{1}{c}{ Results } \\
\cline { 2 - 3 } & \multicolumn{1}{c}{ Expected } & Testing \\
\hline Homepage & Displays the main system page & Success \\
Donation & Showing donation page & Success \\
Register & Displays the registration page and form validation & Success \\
Login & Displays the login page and form validation & Success \\
Gallery & Displays the e-Panti gallery page & Success \\
Activity & Displays the orphan activity page & Success \\
Contact & Displays the web contact page & Success \\
About & Displays about web pages & Success \\
\hline
\end{tabular}

\subsection{Public test questionnaire (beta test)}

Questionnaires were given to users as respondents to test the level of acceptance of the ePanti system by utilizing Google Forms. The following is a list of questions given to 40 respondents consisting of Management, Donors and Foster Children.

1. The e-Panti user interface is interesting

2. The e-Panti user interface is easy to understand

3. The e-Panti is easy to use

4. The information displayed on the orphanage information system is useful

5. This orphanage information system can help donors to make donations online

6. The orphanage information system provides a fast response

7. The menus and navigation on e-Panti are easy to understand

8. I feel satisfied after using this orphanage information system

9. I want to have this orphanage information system

10. I would recommend this orphanage information system relations or relatives 
Table 2 displays the questionnaire calculation results using the percentage calculation with Equation 1:

$$
\text { Percentage Results }(\%)=(N R R / N R) \times 100 \%
$$

Information:

NRR = Number of Respondent Ratings

NR $\quad=$ Number of Respondent

Table 2. Questionnaire calculation results.

\begin{tabular}{ccccc}
\hline Question No. & \multicolumn{3}{c}{ Answer } \\
\cline { 2 - 5 } & \multicolumn{2}{c}{ Yes } & Total & No \\
\cline { 2 - 5 } & Total & \% & 11 & 27.50 \\
\hline 1 & 29 & 72.50 & 10 & 25.00 \\
3 & 30 & 75.00 & 7 & 17.50 \\
4 & 33 & 82.50 & 12 & 30.00 \\
5 & 28 & 70.00 & 11 & 27.50 \\
6 & 29 & 72.50 & 8 & 20.00 \\
7 & 32 & 80.00 & 10 & 25.00 \\
8 & 30 & 75.00 & 7 & 17.50 \\
9 & 33 & 82.50 & 97 & 22.50 \\
10 & 31 & 77.50 & 5 & 12.50 \\
\hline Total & 35 & 87.50 & $\mathbf{9 0}$ & $\mathbf{2 2 . 5 0}$ \\
\hline
\end{tabular}

The results of the questionnaire calculation in the table above show that 40 respondents gave a $77.50 \%$ positive response to this system. Thus, being able to help approve the orphanage's information system can help users make donations easily.

The difference when compared with existing systems such as "rumah yatim" and "kita bisa" e-Panti is not a third-party fundraising site but an open source system that can be used by orphanages themselves. 


\section{Conclusion}

The results of this study can be concluded as follows:

1. One source of funds and donations to orphanages in various developed and developing countries comes from several online donation sites on the internet. In Indonesia there are still many orphanages which have many financial, facilities and affective limitations. Donations from various parties are needed to support the growing number of foster children.

2. Some orphanages can try to implement this system. With this system, orphanages can be better known through complete information on the website. Generous can see the profile of the orphanage, the list of foster children, schedule of activities of the orphanage, and how to make a donation.

3. Based on the questionnaire calculation results, 40 respondents gave a $77.50 \%$ positive response to this system. Thus, being able to help approve the orphanage's information system can be used easily and can help users to make donations easily.

4. e-Panti is not a third-party fundraising site but an open source system that can be used by orphanages themselves.

Acknowledgments. Thanks to the Directorate General of Strengthening Research and Development of the Ministry of Research, Technology and Higher Education of the Republic of Indonesia for funding so that this research can be carried out.

\section{References}

[1] Taumimiyah, S. F.: Mekanisme survival panti asuhan di era modern (studi kasus pada yayasan panti asuhan Assalafiyah Desa Kedung Baruk, Kecamatan Rungkut. Surabaya). Thesis. Universitas Airlangga, Surabaya, Indonesia (2017)

[2] Gooyabadi, M.: Considerations for transparent donation systems: proposing a new donation system for Indian orphanages. Thesis. University of Colorado Boulder, Colorado, USA (2011)

[3] Sutabri, T.: Konsep sistem informasi. CV Andi Offset, Yogyakarta, Indonesia (2012)

[4] Winarno, E., Zaki, A., SmitDev Community: Buku sakti pemrograman PHP. PT. Elex Media Komputindo, Jakarta, Indonesia (2013)

[5] Triandini, E., Suardika, I. G.: Step by step desain proyek menggunakan UML. CV Andi Offset, Yogyakarta, Indonesia (2012)

[6] Utaminingsih, S., Hidayati, R.: Manajemen pengasuhan anak berbasis soft skill di Panti Darul Hadlonah Demak. Vol. 9, No. 2, pp. 341-362. Palastren (2016)

[7] Pressman, R. S.: Software engineering: A practitioner's approach. McGraw-Hill, New York, America (2014) 